\section{THROMBOLYSIS AND ENDOVASCULAR FLOW NETWORK (TEFLON) TRIAL - A NOVEL SYSTEMS-BASED APPROACH TOWARDS REDUCING REPERFUSION TREATMENT DELAYS ACROSS TWO MAJOR COMPREHENSIVE STROKE CENTRES IN SYDNEY}

Sonu Bhaskar' ${ }^{1,2,3,4,5 *}$, Dennis Cordato ${ }^{1,4,5,6}$, Cecilia Cappelen-Smith',4,6, Andrew Cheung7,8,9,4, Nathan Manning ${ }^{7,4,8,9}$, Sandy Middleton'10, Paul Middleton ${ }^{6,1}$, Alessandro Zagami',8, Alan McDougall 1,6,4, Jason Wenderoth ${ }^{7,4,8,9}$, Christopher Levi 1,2,3,4,5,6

\section{BACKGROUND AND AIMS}

Speedy delivery is a crucial factor in ensuring reperfusion therapy approaches deliver most benefit per unit cost. Systems based approaches in reducing the time to reperfusion are important in delivery of best patient outcomes and best value care. Using a combination of adaptive collaborative workflow embedded within a knowledge translation framework, Thrombolysis and Endovascular WorkFLow Network (TEFLON) aims to test a system strategy to better deliver high-value care in reperfusion interventions by reducing treatment delays.

\section{DESIGN: pre-test post-test controlled trial design}

\section{SPECIFIC AIMS}

* Identify existing systemic gaps and barriers to improved systems for reperfusion treatment delivery.

* To develop the design of TEFLON and test the feasibility of TEFLON package in delivering optimal care to AIS patients in south-west and southeast Sydney.

* To test the efficacy of TEFLON in improving treatment delays compared to the conventional model.

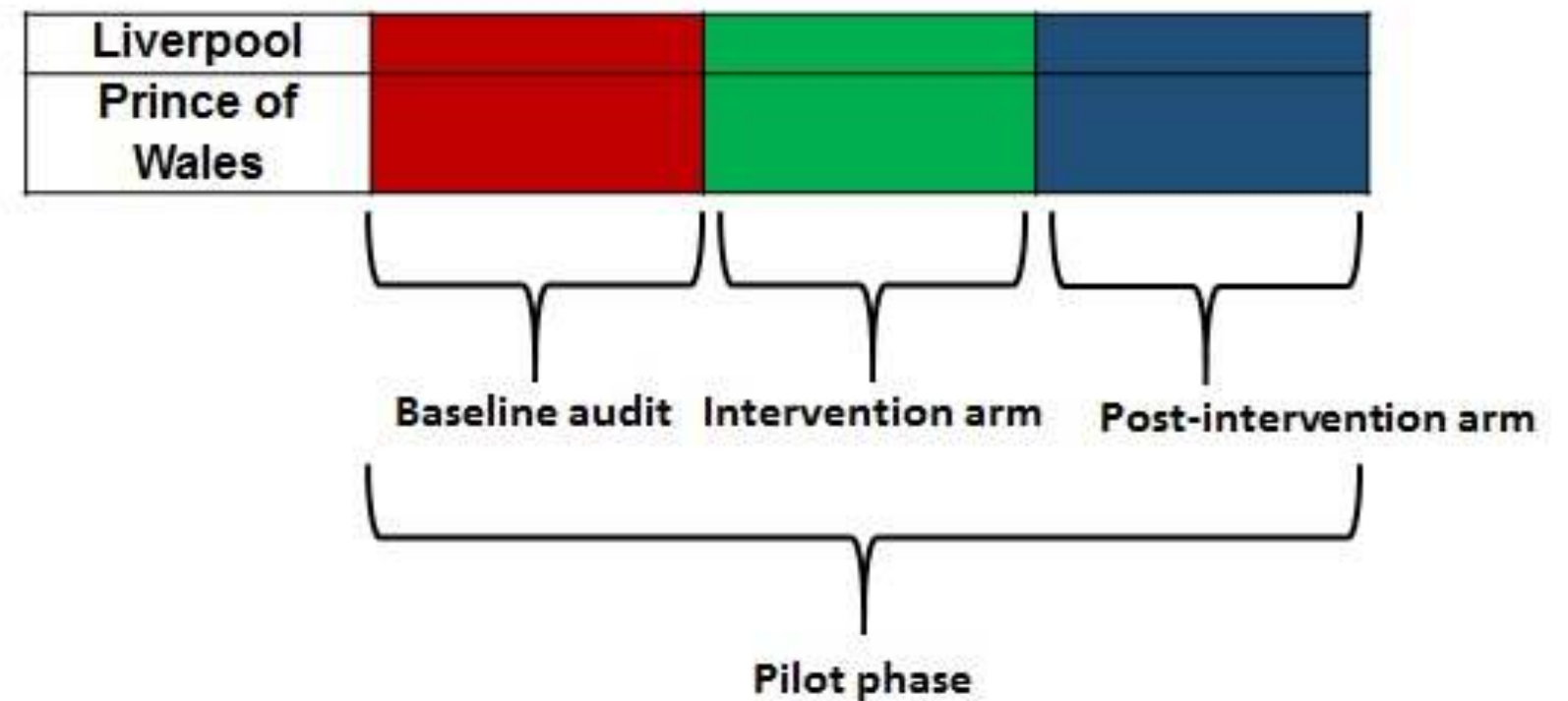

Cluster exposed to TEFLON intervention

Baseline audit and assessment of system gaps

Figure 1. Initial testing phase of TEFLON implementation, across southwest (Liverpool) and southeast (Prince of Wales) Sydney hospitals, incorporating baseline audit, and intervention arms.

\section{METHODS}

This is an implementation and knowledge transfer trial of a package intervention aiming to identify and address system of care gaps in acute stroke reperfusion treatment delivery across two Comprehensive Stroke Centres (CSCs) in Sydney, Liverpool and Prince of Wales Hospitals. Following a baseline phase, processes of care are being mapped and measured, clinicians and management stakeholders are being consulted, and a new workflow model of care is being developed - the TEFLON systembased model. We will then conduct a preliminary pre- versus postimplementation controlled trial of the TEFLON model (Fig 1).

\section{BASELINE AUDIT PHASE}

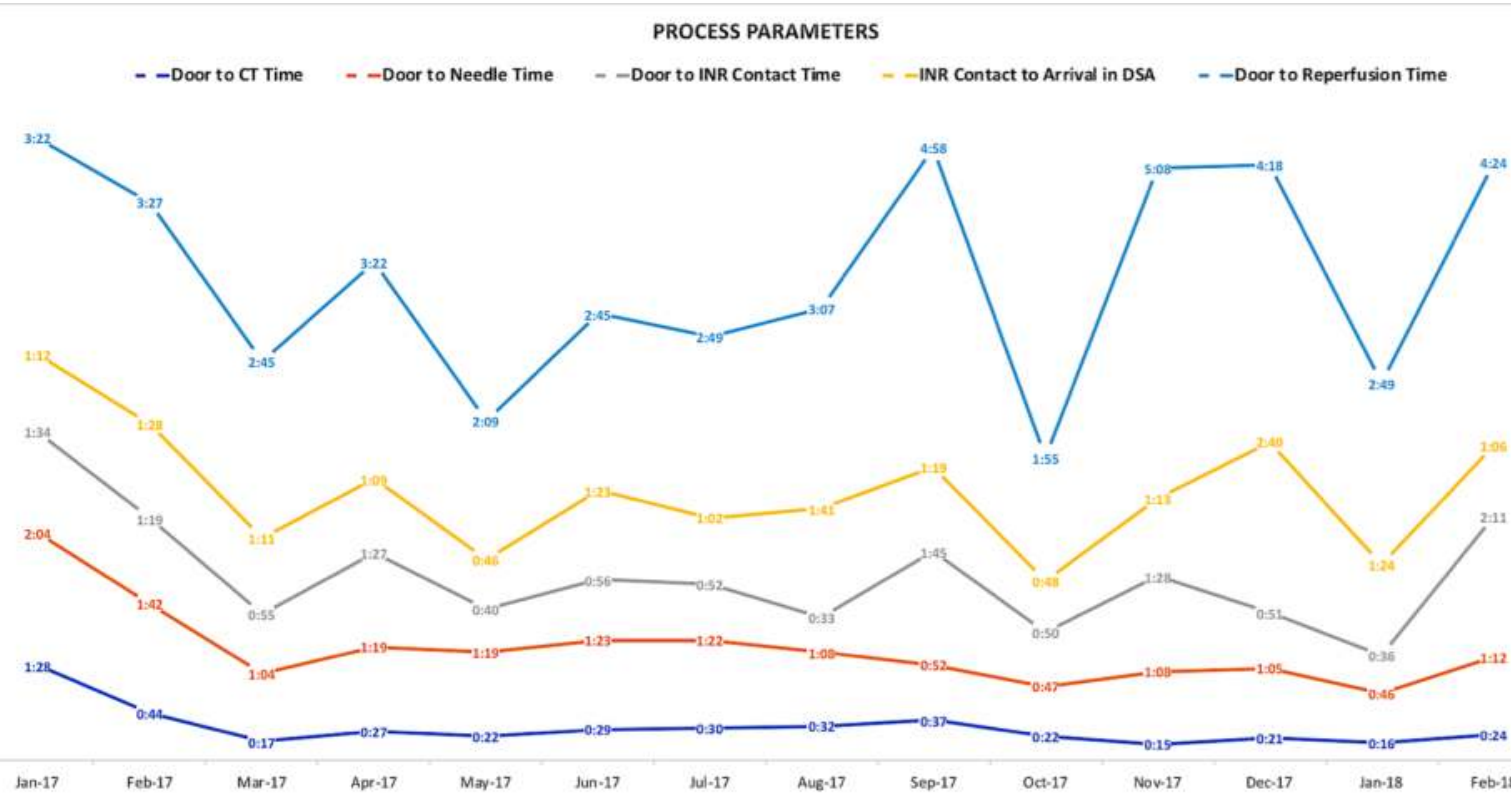

\section{Clinical Practice Improvement - TEFLON Model What are we trying to accomplish?}

Develop a multifactorial, systems based TEFLON intervention strategy involving a multidisciplinary stroke care pathway to reduce treatment delays in reperfusion treatment delivery.

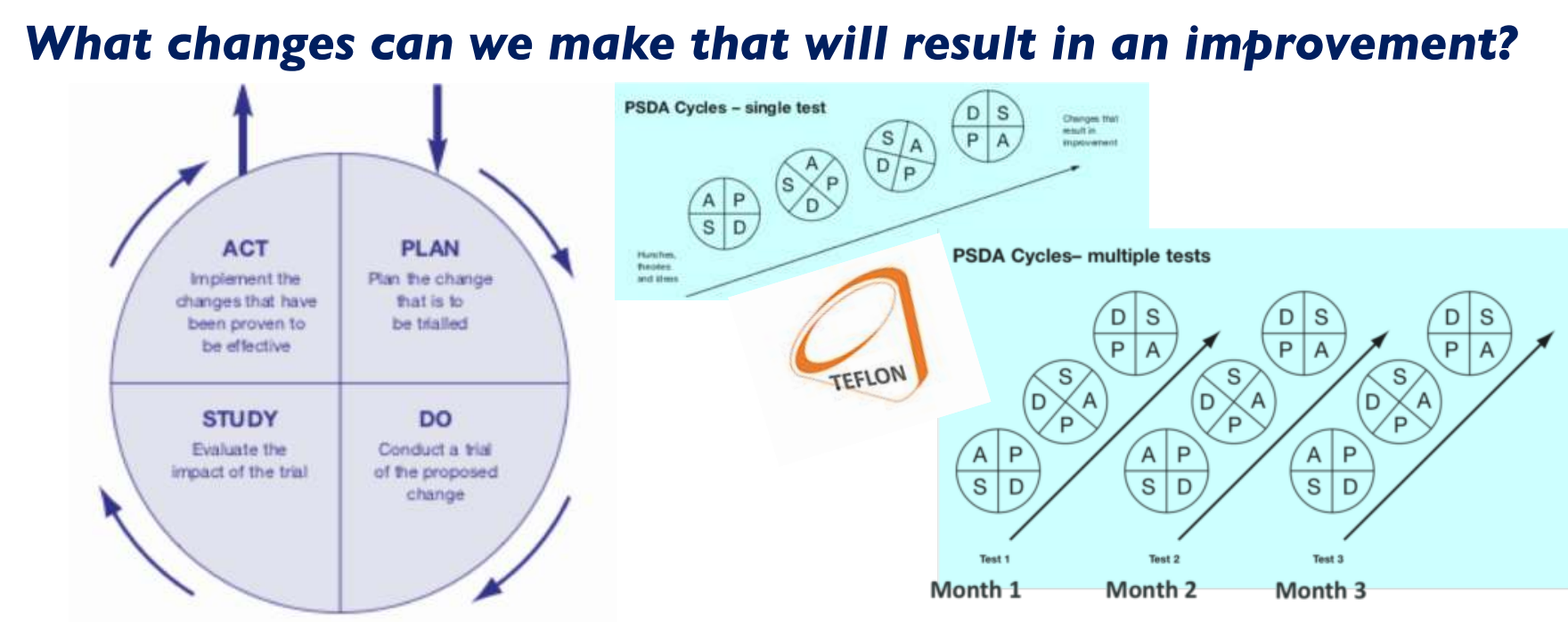

How will we know that a change is an improvement? That is, what do we need to measure?

The TEFLON Cycle - The Improvement "Wheel"
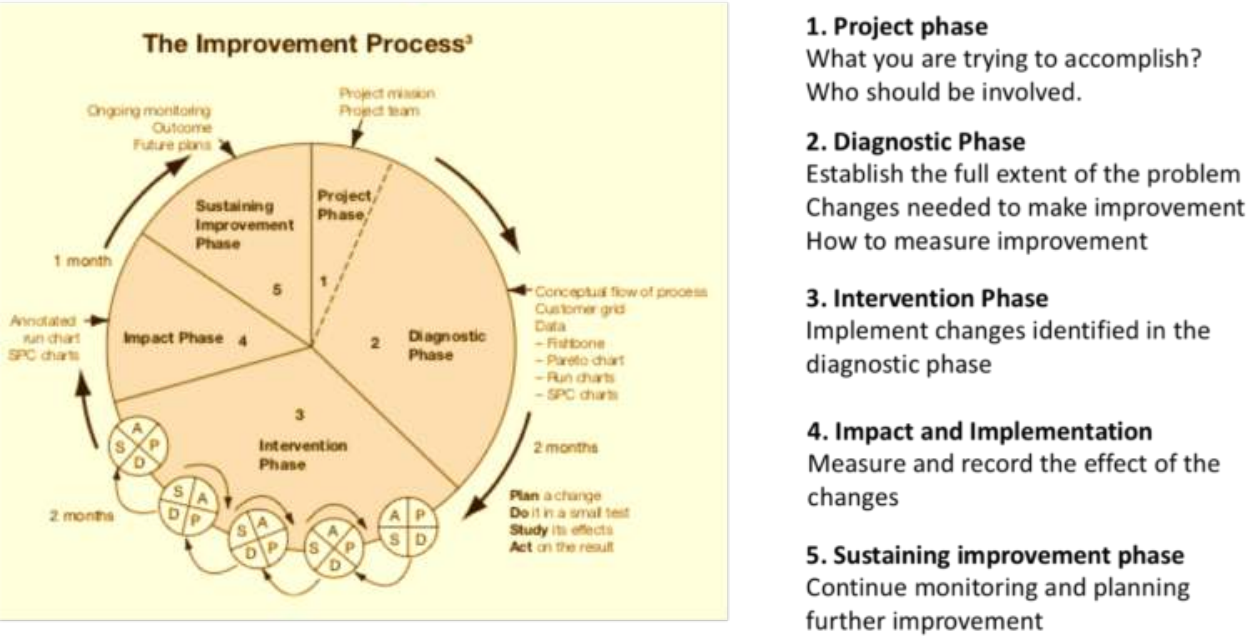

RESULTS

Our baseline audit phase has led to recognition of processes and shared development of multidisciplinary collaborative TEFLON intervention package. The package is being developed and will be introduced in PSDA cycles over the intervention period. The primary outcomes of this initial phase of TEFLON will be improvements in the process of care and in reducing treatment delays - specifically clinically meaningful reductions in door to needle or groin time (DNT/DGT) of 20 minutes.

TEFLON model will result in improved care, cost savings, improved stakeholders satisfaction, and improved clinical outcome. For the long-term sustainability, we will capitalise on the gains achieved vis a vis process parameters, monitor and suggest further improvement and plan wider roll-out.

\section{CONCLUSION AND POLICY ROLL-OUT}

If successful, this model will provide improved efficiency in the delivery of reperfusion therapy across two major hospitals in Sydney. This will provide a strong platform for state-wide reperfusion therapy policy framework and an opportunity for citywide (Sydney), state-wide (NSW), and potentially national rollout of a system-based reperfusion implementation plan (Fig 2).

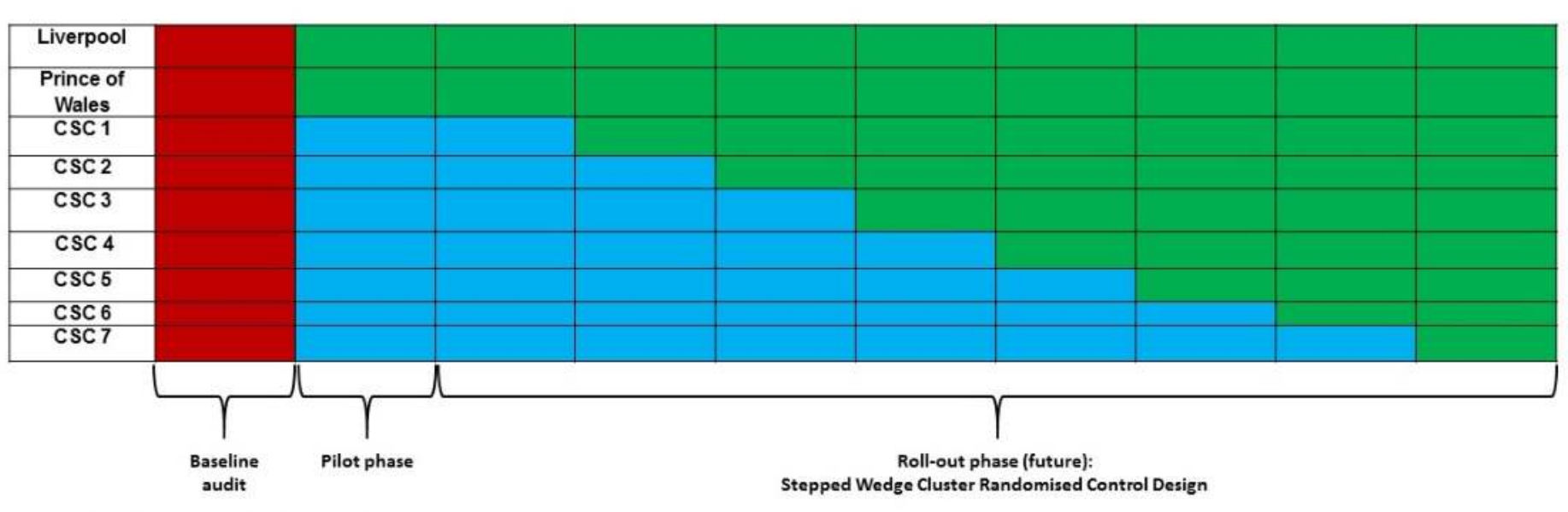

\section{Cluster unexposed to TEFLON interention (controf
Cllster exposed to TEFLNN intevention
Baseine audit and assessment of system gaps}

Figure 2. Proposed future rollout of TEFLON implementation based on a stepped-wedge cluster randomised trial design across Sydney, NSW and Australia.

Copyright (c) 2018 Sonu Bhaskar et al ESOC 20I8, Gothenburg, Sweden *Email: Sonu.Bhaskar@health.nsw.gov.au 